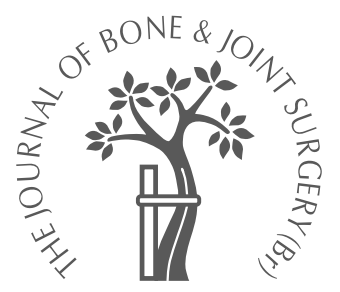

W. Schneider, N. Aigner, O. Pinggera, K. Knahr

From the Orthopaedic Hospital Vienna Speising, Vienna, Austria

W. Schneider, MD, Senior Resident, Orthopaedic Surgeon

N. Aigner, MD, Resident, Orthopaedic Surgeon O. Pinggera, MD, Resident, Orthopaedic Surgeon K. Knahr, MD, Orthopaedic Surgeon, Professor and Head of Department Second General Orthopedic Department, Orthopedic Hospital Vienna - Speising, Speisingerstrasse 109, A-1130 Vienna, Austria.

Correspondence should be sent to Dr W. Schneider.

(C)2004 British Editorial Society of Bone and Joint Surgery doi:10.1302/0301-620X.86B7. $15108 \$ 2.00$

$J$ Bone Joint Surg [Br] 2004;86-B:1016-20.

Received 6 November 2003; Accepted after revision 24 March 2004

\title{
Chevron osteotomy in hallux valgus
}

\author{
TEN-YEAR RESULTS OF 112 CASES
}

The Chevron osteotomy was described in 1976. There have, however, been only short- to mid-term follow-up reviews, often with small numbers of patients.

We looked at 112 feet (73 patients) with a minimum follow-up of ten years following Chevron osteotomy with a distal soft-tissue procedure. Clinical evaluation was calculated using the hallux score of the American Orthopedic Foot and Ankle Society (AOFAS). For 47 feet (30 patients), the results were compared with those from an interim follow-up of 5.6 years.

The AOFAS-score improved from a pre-operative mean of 46.5 points to a mean of 88.8 points after a mean of $\mathbf{1 2 . 7}$ years. The first metatarsophalangeal (MTP) angle showed a mean pre-operative value of $27.6^{\circ}$ and was improved to $14.0^{\circ}$. The first intermetatarsal (IM) angle improved from a pre-operative mean value of $13.8^{\circ}$ to $8.7^{\circ}$. The mean pre-operative grade of sesamoid subluxation was 1.7 on a scale from 0 to 3 and improved to 1.2.

Measured on a scale from 0 to 3, arthritis of the first MTP joint progressed from a mean of 0.8 to 1.7. Comparing the results in patients younger and older than $\mathbf{5 0}$ years, the Chevron osteotomy performed equally in both age groups. Analysing the subgroup of 47 feet with a post-operative follow-up of both $\mathbf{5 . 6}$ and 12.7 years, the AOFAS pain and the overall score showed a further improvement between both follow-up evaluations. The MTP angle, first IM angle and sesamoid position remained unchanged. The progression of arthritis of the first MTP joint between $\mathbf{5 . 6}$ and $\mathbf{1 2 . 7}$ years post-operatively was statistically significant. Only one patient required a revision procedure due to painful recurrence of the deformity.

Excellent clinical results following Chevron osteotomy not only proved to be consistent, but showed further improvement over a longer follow-up period. The mean radiographic angles were constant without recurrence of the deformity. So far, the statistically significant progression of first MTP joint arthritis has not affected the clinical result, but this needs further observation.

Since $1976,{ }^{1}$ when first described, the Chevron procedure has gained popularity for the correction of mild to moderate hallux valgus. Combining the osteotomy with soft-tissue realignment at the first metatarsophalangeal (MTP) joint extended its indications to include more severe deformities. ${ }^{2-4}$ Although this procedure can achieve good results in an older population, ${ }^{3}$ the main indication is the younger and more active patient. This requires good long-term results with relief of pain, restoration of function and permanent correction of the deformity. Most reports present short- to mid-term results, often with only small numbers of patients. The aim of our study was to evaluate clinical and radiographic results of a substantial number of patients with a longer period of follow-up.

\section{Patients and Methods}

Between 1989 and 1992 a total of 130 Chevron osteotomies combined with a distal softtissue procedure were performed in 90 patients. A total of 73 patients (112 feet) with a minimum follow-up of ten years were available for clinical and radiographic analysis. One patient had died and 16 had moved and were lost to follow-up. The mean follow-up was 12.7 years (10.0 to 14.6$)$. There were 65 women (103 feet) and eight men (nine feet). The mean age at time of surgery was 48.1 years (21.7 to 69.1). As part of a previously published study, ${ }^{3} 47$ of these osteotomies (30 patients) had been reviewed at a mean of 5.6 years after surgery (5.0 to 7.6$)$ using the same criteria for clinical and radiographic assessment. 
Table I. Classification of medial sesamoid displacement according to Smith, Reynolds and Stewart ${ }^{13}$

Grade $0 \quad$ No displacement of sesamoid relative to the longitudinal axis of the first metatarsal

Grade $1 \quad$ Overlap of less than $50 \%$ of sesamoid to the longitudinal metatarsal axis

Grade $2 \quad$ Overlap of greater than $50 \%$ of sesamoid to the longitudinal metatarsal axis

Grade $3 \quad$ Sesamoid completely displaced beyond the longitudinal axis of the first metatarsal

Table II. Radiographic signs of arthritis of the first MTP joint according to Regnauld ${ }^{14}$

\begin{tabular}{ll}
\hline Normal articulation & $\begin{array}{l}\text { Absence of radiographic abnormalities of the MTP joint } \\
\text { First degree }\end{array}$ \\
& $\begin{array}{l}\text { Condensation of bone around the periphery } \\
\text { Slight narrowing of the joint space } \\
\text { Diminution in the convexity of the metatarsal head mirrored by the opposing phalanx } \\
\text { Sesamoids are regular but slightly enlarged compared with normal }\end{array}$ \\
Second degree & $\begin{array}{l}\text { General narrowing of the joint space with peripheral condensation } \\
\text { Irregular flattened configuration of the joint shape } \\
\text { Hypertrophy of the subarticular bone with eburnation } \\
\text { Irregular hypertrophy of the sesamoids }\end{array}$ \\
Third degree & $\begin{array}{l}\text { Complete disappearance of the joint space } \\
\text { Hypertrophy of bony elements - metatarsal, phalanx, sesamoids } \\
\text { Osteophytes from the sesamoids may bridge the undersurface }\end{array}$
\end{tabular}

The indication for a Chevron osteotomy with a distal soft-tissue procedure was painful hallux valgus with an adequate range of movement (ideally combined dorsiflexion and plantar flexion of $>60^{\circ}$ ) but without a strict limit to the angular deformity. Surgery was carried out under local anaesthesia and an ankle tourniquet. A single dorsomedial skin incision was used to expose the medial aspect of the MTP joint and first webspace. Two Faraboeuf retractors were then inserted into the first webspace to expose the lateral articular capsule. A lateral capsulotomy was made with division of the lateral collateral ligament. The contracted fibrous structures between the lateral tubercle of the metatarsal head and the lateral border of the lateral sesamoid (i.e. the lateral metatarsosesamoid suspensory ligament) were released. The attachment of the adductor muscle to the base of the proximal phalanx was divided. This procedure left the attachment of the dorsal and plantar capsule and the deep intermetatarsal (IM) transverse ligament intact. Exposure and resection of the medial eminence and the osteotomy itself were carried out using the standard technique. ${ }^{1,5-7}$ No internal fixation was used. A medial capsular repair pushed the metatarsal head laterally with concomitant correction of sesamoid displacement and both MTP and IM angles. A similar soft-tissue procedure was first published by LeLièvre and LeLièvre ${ }^{8}$ in 1967 as the "Cerclage fibreux" technique. Mobilisation fully weightbearing began on the second post-operative day using a stiff-soled shoe for six weeks. An elastic adhesive bandage was applied and adjusted each week for six weeks in order to maintain the correction. Patients were educated to mobilise their first MTP joint manually during this period.

The pre-operative protocol included assessment of the severity and site of pain, the need for medication or walking aids, limitations of general activity, sporting ability, require- ments for footwear, problems on uneven surfaces, MTP and interphalangeal (IP) joint movement, the presence of bunion, calluses and cosmesis. This allowed retrospective conversion into the 'hallux score' according to the American Orthopaedic Foot and Ankle Society (AOFAS), ${ }^{9}$ although this score had been first published in 1994. All post-operative assessment included examination of the patient, again using the AOFAS hallux score, evaluating pain, limitation of activity, footwear, MTP joint movement (combined dorsiflexion and plantar flexion), IP joint movement (plantar flexion), stability of the MTP and IP joints, tender calluses and alignment. Plain weight-bearing AP radiographs were used pre- and post-operatively to measure the

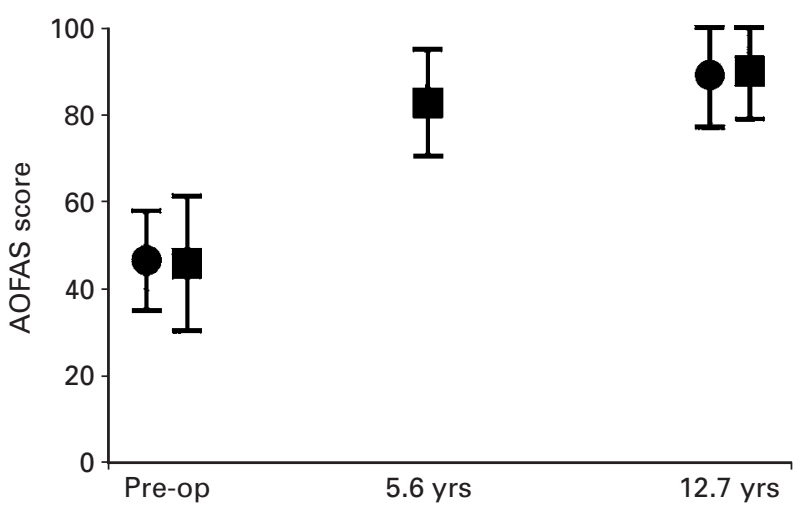

Fig. 1

AOFAS hallux score before, 5.6 and 12.7 years after Chevron osteotomy. Mean values \pm SD. Circles show results of all 112 cases, squares indicate results of subgroup with additional interim follow-up 5.6 years after surgery. 


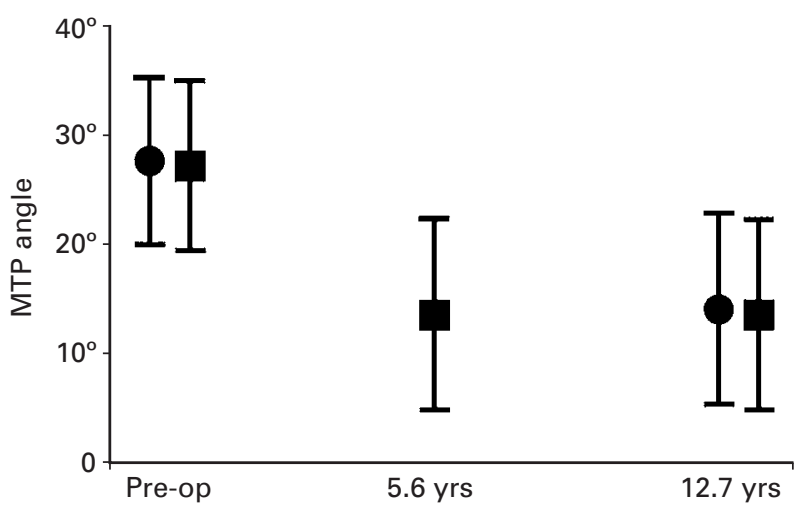

Fig. 2

First MTP angle before, 5.6 and 12.7 years after Chevron osteotomy. Mean values \pm SD. Circles show results of all 112 cases, squares indicate results of subgroup with additional interim follow-up 5.6 years after surgery.

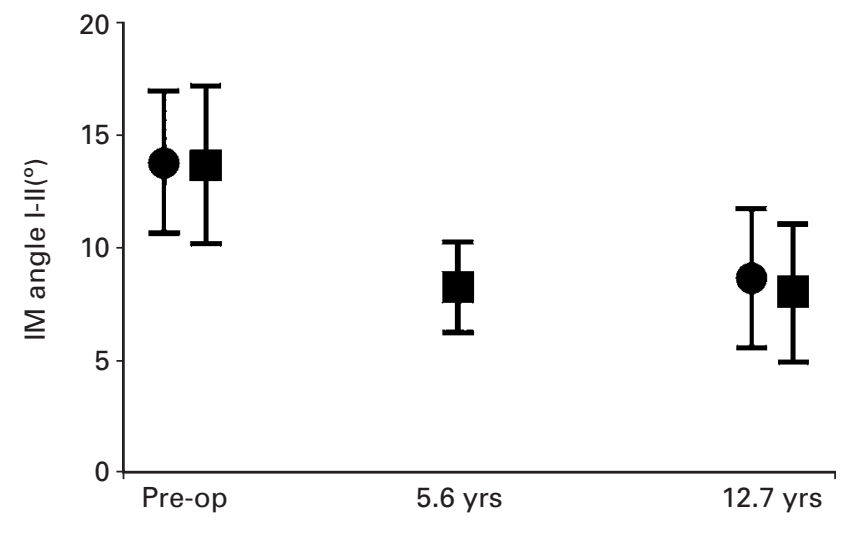

Fig. 3

First IM angle before, 5.6 and 12.7 years after Chevron osteotomy. Mean values \pm SD. Circles show results of all 112 cases, squares indicate results of subgroup with additional interim follow-up 5.6 years after surgery.

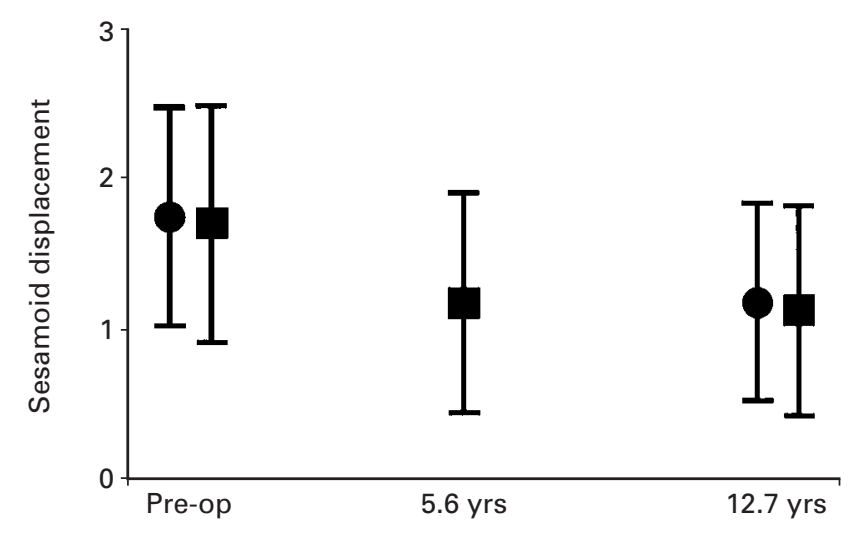

Fig. 4

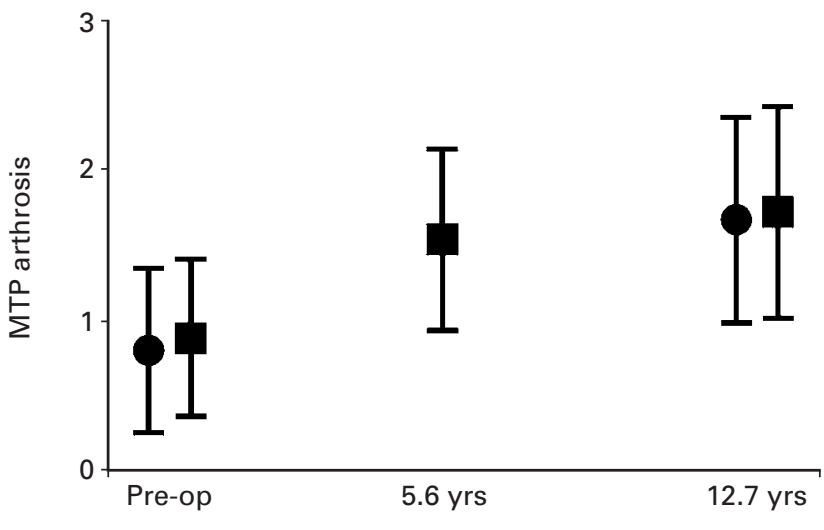

Fig. 5

Sesamoid subluxation grade before, 5.6 and 12.7 years after Chevron osteotomy. Mean values \pm SD. Circles show results of all 112 cases, squares indicate results of subgroup with additional interim follow-up 5.6 years after surgery.

MTP and IM angles as was described by Miller, ${ }^{10}$ Schneider and $\mathrm{Knahr}^{11}$ and Schneider, Csepan and Knahr, ${ }^{12}$ using the centre of the head and base of the first metatarsal as reference points for drawing the axis of the first metatarsal. Subluxation of the medial sesamoid was graded from 0 to 3 according to Smith, Reynolds and Stewart ${ }^{13}$ (Table I). Arthritis of the MTP joint was evaluated in accordance with the description of Regnauld ${ }^{14}$ (Table II). Wilcoxon's signed rank test (two-tailed) served to compare findings at different periods of follow-up. Mann-Whitney U-test was used to compare two age groups younger and older than 50 years.

\section{Results}

Assessing the results of all 112 Chevron osteotomies, the AOFAS-score improved from a pre-operative mean of 46.5

points (20 to 70 ) to a mean of 88.8 points ( 44 to 100 ) after a mean of 12.7 years (Fig. 1). Dividing the AOFAS score into pain, function and alignment, we found an improvement from a mean pre-operative score of 14.8 points ( 0 to 30 ) to 36.9 points ( 0 to 40 ) for pain, from 30.3 points (19 to 40 ) to 39.4 points (27 to 45$)$ for function and from 1.3 points ( 0 to 15 ) to 12.6 (0 to 15 ) for alignment. The mean range of movement of the first MTP joint (combined dorsiflexion and plantar flexion) was $73.8^{\circ}$ (35 to 135 ) pre-operative and $72.6^{\circ}$ (25 to 135 ) at follow-up.

The mean first MTP angle improved from $27.6^{\circ}$ (13 to $50)$ pre-operatively to $14.0^{\circ}$ ( -10 to 36 ; Fig. 2$)$. The mean first IM angle improved from $13.8^{\circ}$ ( 7 to 24 ) to $8.7^{\circ}$ (1 to 18; Fig. 3). The mean grade of subluxation of the medial sesamoid improved from 1.7 (0 to 3 ) on a scale from 0 to 3 
Table III. Clinical and radiographic data of 47 cases with an additional follow-up after 5.6 years (range)

\begin{tabular}{|c|c|c|c|c|}
\hline & Pre-operative & $\begin{array}{l}\text { First follow-up } \\
\text { mean } 5.6 \text { yrs }\end{array}$ & Level of significance* & $\begin{array}{l}\text { Second follow-up } \\
\text { mean } 12.7 \text { yrs }\end{array}$ \\
\hline AOFASt hallux score & $\begin{array}{l}45.8 \\
(20 \text { to } 70)\end{array}$ & $\begin{array}{l}82.5 \\
(47 \text { to } 100)\end{array}$ & $\mathrm{p}<0.001$ & $\begin{array}{l}89.7 \\
(54 \text { to } 100)\end{array}$ \\
\hline AOFAS score - pain & $\begin{array}{l}13.0 \\
(0 \text { to } 30)\end{array}$ & $\begin{array}{l}31.9 \\
(0 \text { to } 40)\end{array}$ & $p<0.001$ & $\begin{array}{l}37.4 \\
(20 \text { to } 40)\end{array}$ \\
\hline AOFAS score - function & $\begin{array}{l}29.6 \\
(19 \text { to } 40)\end{array}$ & $\begin{array}{l}38.6 \\
(24 \text { to } 45)\end{array}$ & ns & $\begin{array}{l}39.3 \\
(29 \text { to } 45)\end{array}$ \\
\hline AOFAS score - alignment & $\begin{array}{l}3.2 \\
(0 \text { to } 15)\end{array}$ & $\begin{array}{l}12.0 \\
(0 \text { to } 15)\end{array}$ & ns & $\begin{array}{l}13.0 \\
(0 \text { to } 15)\end{array}$ \\
\hline $\begin{array}{l}\text { MTP } \ddagger \text { range of motion }\left({ }^{\circ}\right) \\
\text { (dorsiflexion + plantar flexion) }\end{array}$ & $\begin{array}{l}73.8 \\
(35 \text { to } 135)\end{array}$ & $\begin{array}{l}82.8 \\
(15 \text { to } 135)\end{array}$ & $p=0.01$ & $\begin{array}{l}77.3 \\
(25 \text { to } 135)\end{array}$ \\
\hline MTP angle & $\begin{array}{l}27.1 \\
(13 \text { to } 45)\end{array}$ & $\begin{array}{l}13.5 \\
(-10 \text { to } 40)\end{array}$ & ns & $\begin{array}{l}13.5 \\
(-10 \text { to } 34)\end{array}$ \\
\hline IM angle & $\begin{array}{l}13.7 \\
(7 \text { to } 24)\end{array}$ & $\begin{array}{l}8.3 \\
\text { (3 to } 14)\end{array}$ & ns & $\begin{array}{l}8.1 \\
(3 \text { to } 15)\end{array}$ \\
\hline Sesamoid subluxation grade & $\begin{array}{c}1.7 \\
(0 \text { to } 3)\end{array}$ & $\begin{array}{c}1.2 \\
(0 \text { to } 3)\end{array}$ & ns & $\begin{array}{c}1.1 \\
(0 \text { to } 3)\end{array}$ \\
\hline Arthritis & $\begin{array}{c}0.9 \\
\text { (0 to } 2)\end{array}$ & $\begin{array}{c}1.5 \\
(0 \text { to } 3)\end{array}$ & $p=0.009$ & $\begin{array}{c}1.7 \\
(0 \text { to } 3)\end{array}$ \\
\hline
\end{tabular}

* significance levels refer to differences between the two follow-up investigations 5.6 and 12.7 years after surgery. Wilcoxon's signed rank test (two-tailed).

$\dagger$ American Orthopaedic Foot and Ankle Society ${ }^{9}$

‡ MTP metatarsophalangeal; IM, intermetatarsal)

to 1.2 (0 to 3; Fig. 4). Arthritis of the first MTP joint from a mean of 0.8 (0 to 2$)$ to 1.7 (0 to 3) (Fig. 5).

Analysing the subgroup of 47 cases with an additional follow-up carried out after 5.6 years, we found no differences in radiographic parameters such as the first MTP angle, first IM angle and grade of subluxation of the medial sesamoid between 5.6 and 12.7 year follow-up (Table III). Progression of arthritis in the first MTP joint was statistically significant $(\mathrm{p}=0.009)$. The mean range of movement of the first MTP joint decreased slightly from $82.8^{\circ}$ to $77.3^{\circ}$ $(\mathrm{p}=0.01)$ between the two follow-up assessments. The improvement of the clinical variables which were measured in the 5.6- to 12.7-year follow-up were not statistically significant for AOFAS function and alignment score, but significant for AOFAS pain score $(\mathrm{p}<0.001)$ and AOFAS overall score ( $\mathrm{p}<0.001)$ (Figs 1 to 5$)$.

Comparing the results in patients younger than 50 years (71) at time of surgery with those older than 50 years (41), no statistically significant differences were found for any of the parameters mentioned above.

The following early complications were recorded: three minor superficial infections without need for antibiotic treatment and six infections which were treated with antibiotics, three cases of reversible hypoaesthesia in the region of the wound, one delayed union of the osteotomy was treated by reduced weight-bearing until complete radiographic union was seen at five months. Two patients developed partial avascular necrosis of the metatarsal head combined with advanced arthritis of the first MTP joint
(Fig. 6) as late complications; they were, however, painfree with AOFAS scores at 95 and 100 points respectively. One patient had a revision procedure due to painful recurrence of hallux valgus after eight years, with a Keller's resection arthroplasty.

\section{Discussion}

Analysing proposed algorithms for the surgical treatment of hallux valgus, ${ }^{7,15,16}$ it has been suggested that the Chevron osteotomy should only be undertaken in patients younger than 50 years of age ${ }^{7}$ with an MTP angle less than $30^{\circ}$, an IM angle less than $15^{\circ}$ and no degenerative changes in the MTP joint. $5,7,16,17$

The results after a mean follow-up of 12.7 years justify the routine use of the Chevron osteotomy. The clinical and radiographic results are good, with only one revision in 112 osteotomies, due to painful recurrence of the deformity. The AOFAS hallux score improved in both pain and function and radiographic analysis showed good correction of both the MTP angle and the first IM angle to physiological mean values.

Analysing differences between the 5.6- and 12.7-year post-operative follow-up, there was no change in radiographic angles or position of the medial sesamoid. The arthritic changes progressed between these two reviews. There was a marked increase in the degenerative changes of the first MTP joint from the pre-operative values to those at follow-up after 5.6 years. We found no comparable data on the post-operative increase of degenerative changes follow- 


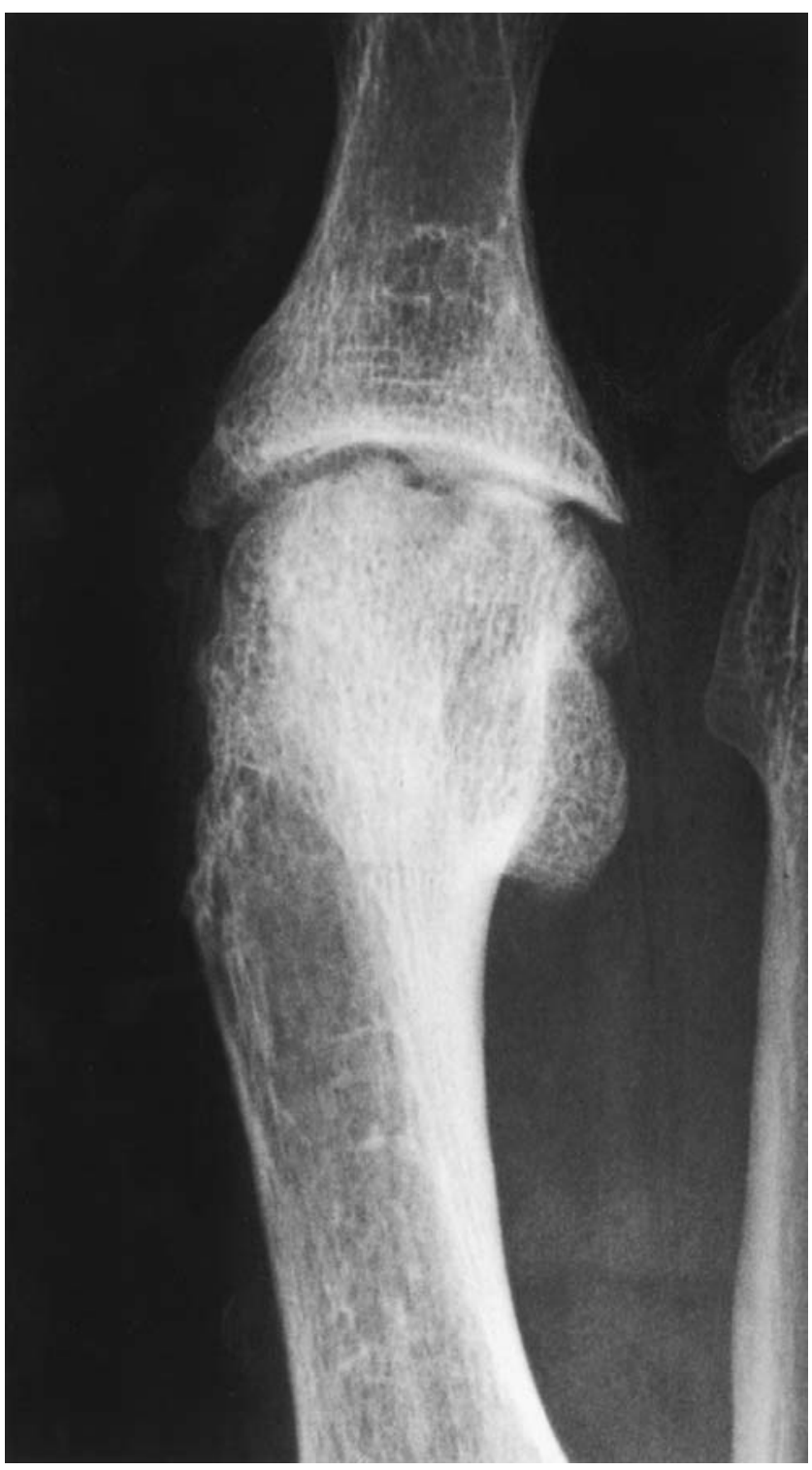

Fig. 6

Radiograph showing partial avascular necrosis of the first metatarsal head ten years after Chevron osteotomy. The patient was pain-free, with a slight reduced range of movement.

ing Chevron osteotomy in the literature. The clinical outcome was not affected by the degenerative changes, except for a slight decrease in the range of movement of the first MTP joint.

Two patients developed partial avascular necrosis of the first metatarsal head, which can be attributed to vascular disturbances related to surgery (Fig. 6). Special care should be taken when mobilising the soft tissues during the lateral release in order to avoid damage to the articular surface and disturbance of the blood supply. ${ }^{18,19}$

Clinical results, based on the AOFAS hallux score showed an improvement in the overall result, as well as in relief of pain and function between the two follow-up assessments. The radiographic results remained nearly unchanged.

Although most authors recommend that the Chevron osteotomy should be used only for patients who are younger than 50 years of age, we did not impose an age limit, provided that the first MTP joint had sufficient movement without advanced degenerative changes. Comparing patients younger and older than 50 years at time of surgery, we found no differences in the clinical and radiographic outcome and thus the Chevron osteotomy need not be restricted to younger patients.

Three patients had post-operative hypoaesthesia in the area of the wound which resolved some weeks after surgery. Careful surgical technique avoided damage to the dorsomedial nerve of the great toe which runs just beneath the incision.

No benefits in any form have been received or will be received from a commercial party related directly or indirectly to the subject of this article.

\section{References}

1. Corless JR. A modification of the Mitchell procedure. J Bone Joint Surg [Br] 1976; 58-B:138.

2. Pochatko DJ, Schlehr FJ, Murphey MD, Hamilton JJ. Distal chevron osteotomy with lateral release for treatment of hallux valgus deformity. Foot Ankle Int 1994;15: 457-61.

3. Schneider W, Knahr K. Keller procedure and chevron osteotomy in hallux valgus: five-year results of different surgical philosophies in comparable collectives. Foot Ankle Int 2002;23:321-9.

4. Steinböck G. The horizontally directed "V" displacement osteotomy of the metatarsal head according to Austin for the treatment of hallux valgus. Orthopäde 1996;25: 308-16.

5. Johnson KA. Chevron osteotomy. In: Johnson KA, ed. The foot and ankle: master techniques in orthopaedic surgery. New York: Raven Press, 1994:31-48.

6. Johnson KA, Cofield RH, Morrey BF. Chevron osteotomy for hallux valgus. Clin Orthop 1979;142:44-7.

7. Mann RA, Coughlin MJ. Surgery of the foot and ankle. Vol 1. St. Louis, etc: Mosby, 1993:150-269.

8. LeLièvre J, LeLièvre J-F. Technique chirurgicale de l'avant pied. In: LeLièvre J, ed. Pathologie due Pied. Paris: Masson et Cie, 1967:809-12.

9. Kitaoka HB, Alexander IJ, Adelaar RS, et al. Clinical rating systems for the anklehindfoot, midfoot, hallux, and lesser toes. Foot Ankle 1994;15:349-53.

10. Miller JW. Distal first metatarsal displacement osteotomy: its place in the schema of bunion surgery. J Bone Joint Surg [Am] 1974;56-A:923-31.

11. Schneider W, Knahr K. Metatarsophalangeal and intermetatarsal angle: different values and interpretation of postoperative results dependent on the technique of measurement. Foot Ankle Int 1998;19:532-6.

12. Schneider W, Csepan R, Knahr K. Reproducibility of the radiographic metatarsophalangeal angle in hallux surgery. J Bone Joint Surg [Am]2003;85-A:949-9.

13. Smith RW, Reynolds JC, Stewart MJ. Hallux valgus assessment: report of Research Committee of American Orthopaedic Foot and Ankle Society. Foot Ankle 1984;5:92-103

14. Regnauld B. Hallux rigidus. In: Elson R, ed. The foot. Berlin, etc: Springer Verlag, 1986:335-50

15. Borderlon RL. Evaluation and operative procedures for hallux valgus deformity. Orthopaedics 1987;10:38-44.

16. Mann RA. Bunion surgery: decision making. Orthopedics 1990;13:951-7

17. Leventen EO. The chevron procedure. Orthopedics 1990;13:973-6.

18. Lin I, Bonar SK, Anderson RB, Hoges Davis W. Distal soft tissue release using direct and indirect approaches: an anatomic study. Foot Ankle 1996;17:458-63.

19. Jones KJ, Feiwell LA, Freedman EL, Cracchiolo A 3rd. The effect of chevron osteotomy with lateral capsular release on the blood supply to the first metatarsal head. J Bone Joint Surg [Am] 1995;77-A:197-204. 